\title{
The personal is political: reframing individual acts of kindness as social solidarity in social work practice.
}

\author{
Dr Darren Hill. PhD. \\ Reader. \\ Leeds Beckett University. \\ 505 Calverley Building. \\ Leeds, LS1 3HE. \\ Dr Erika Laredo. PhD. \\ Senior Lecturer Youth \& Community Work. \\ Leeds Beckett University. \\ 505 Calverley Building \\ Leeds, LS1 3HE.
}

\begin{abstract}
.
This paper develops the theoretical position proposed by Zygmunt Bauman (2009), that one of the greatest contemporary 'social evils' or injustices we face in society, is the total marketization and individualisation of our lived experience. Bauman (2009) along with Harvey (2005) argues that the last forty years of social, political, and economic reform under the zeitgeist of neoliberalism have transferred the burden of care from the state to the individual. This paper will explore the position that the dominant neoliberal culture within social work, in the form of 'new managerialism' has reconstituted social work institutionally as one where interventions now focus on minimum statutory interventions emphasising; risk management, resource allocation, audit culture, and the promotion of self-care through a case work methodology. The discussion will analyse these macro social, political and economic discourses using an ethnographic approach based upon Michael Burawoy's Global Ethnographic (GE) methodology (Burawoy et al, 2010). Despite the current landscape the research highlights the importance of the personal reframed as the political, and the nuanced ways in which
\end{abstract}


acts of defiance and resistance against the prevailing orthodoxies have been adopted by social workers on the front line.

\section{Keywords: Social Work Practice, New Managerialism, Neoliberalism, Ethnography.}

\section{Introduction.}

Laying claim to the slogan the personal is political (Hanisch, 1969) feminist theory encourages the examination of the public/private divide. In her work, Weeks (2011) argues that the privatising of work is akin to a marriage, suggesting that despite its public, regulated and remunerated position, the workplace is typically configured as a private space. The discussion that follows will examine the public, professional space of social workers informed by a standpoint grounded in a Marxist-Feminist approach with Foucauldian undertones (Foucault, 1997; Weeks, 2011, Fraser, 2013). The epistemological underpinnings of this position necessarily require consideration of broader historical and social materialities, and an understanding that individual acts of solidarity potentially disrupt mainstream orthodoxies. A foundational aim of second wave feminists was to relocate private issues as matters of public concern to show how the small daily grind is clearly linked to larger systemic issues and systemic inequalities, furthermore, Ahmed (2017) argues that the personal is potentially also theoretical, and importantly grounded in everyday experiences.

Our discussion explores the challenges of contemporary practice; practitioners managing the difficulties and stresses of increased caseloads and fewer resources, yet despite these 
constraints, manage to maintain relational practices, making human connections with their service users.

Social work is neither neutral or benign; it is both a conduit and amplifier of the power networks of neo-liberalism. This has resulted in many contradictions given the 'overturning' of embedded liberalism and the marketisation of UK public services resulting in increased inequality and injustice for those accessing welfare support (Garrett, 2019). To understand the myriad ways crisis is experienced by individuals, connections can be made between the private sphere of experience and the public sphere of the political economy. The narrative describing enduring realities about poverty and inequality tell a story, which stigmatises, dehumanises and focuses on the undeserving (Jensen and Tyler 2015). Our research suggests by opening up 'private' professional spaces that manage the lives of citizens is essential to a political debate about social justice.

The paper is informed by ethnography based within two social work organisations; one statutory (Agency A) and one voluntary (Agency B), this is a deliberate choice to highlight how organisational narratives inform individual social work practice. One of the core principles of social work is it is a profession which upholds and advocates for human rights and social justice, and that these rights coexist in an environment of collective responsibility for one another (IFSW, 2012). Whilst this might once have been mainstream and the underpinning of social work training, contemporary practice has become increasingly 
regulated by the imposition of new managerialism resulting in much greater technocratic practices, where managing risk becomes the priority. This focus moves social work away from a rights-based agenda, providing services and promoting better social and material outcomes for individuals' families and communities. We selected two different social work agencies; one statutory working in the field of children's safeguarding working with children and families, delivering formal, conditional, child protection and welfare work to those in need; and the other a voluntary sector NGO working with women involved in street sex work, providing direct unconditional harm reduction based social support to vulnerable adults. The data reveals practices committed to the promotion of human rights, social justice, and the fair distribution of social and material resources. This approach is manifested through discretionary acts; small acts of kindness in order to divert crisis and develop relationships based on social solidarity. Our argument based on a political economy of social work, reframes these acts of personal solidarity and kindness disrupting the prevailing neoliberal orthodoxy, offering instead a tentative framework for a more dynamic practice of community-based social work, premised on relational practice and social solidarity.

\section{Theoretical Framework.}

The paper is informed by a Marxist-Feminist approach (Bauman, 2009; Fraser et al 2014; Polanyi, 2001), which develops a counter narrative to the prevailing orthodoxy of neoliberalism as a common-sense approach to everyday life (Thompson, 2008). Foucault's analysis of power helps us understand that social workers are neither neutral or objective, they are both conduits and active participants of the dominant models of social, economic and 
political practices (Foucault \& Chomsky, 2011). Under neo-liberalism one of the functions of social work is to a practice that nurtures, supports and encourages fully integrated individuals and families who are self-caring, and capable of living independent lives within society free from social work support (Weeks, 2011). We take the position that social work is more than a set of subsidiary economic policies it is a process of solidarity, of supporting others to achieve better social and material relationships.

Social work in the United Kingdom has vacillated between the moral and ethical positions of care and control (Harris, 2008; Payne, 2005). Institutionally framed by a capitalist model, which despite the capacity to meet the needs of all with a just allocation of resources, the 'supposed' efficiency' and success of the model is predicated on the lack of distribution of resources in an equitable manner (Polanyi, 2001). The justification for the enduring existence of poverty and inequality has been the active promotion of a discourse about individualism, the normalisation of this has overseen a wholesale transfer of responsibility of care from the state to the individual (Harvey 2005). In their daily activities social workers encounter the failures of the social and economic order, witnessing poverty and inequality at first hand. Their practice helps to alleviate the worst disordered faults of the system, and soften the suffering caused by changes in the political economy, thus social work can be viewed as a radical practice, one informed by a human rights agenda promoting access to better social and material resources. Over the last decade there has been a concerted agenda to de-politicise social work, and simultaneously to present it as a more neutral, benign and technocratic profession (Ferguson \& Woodwood, 2009). The process of depoliticising 
welfare forms part of a wider discourse that seeking to normalise injustice and structural violence such as poverty and inequality, and transfer responsibility from a macro narrative dealing with social, political and economic contexts, to the micro context of the individual worker and citizen.

The neoliberal period has promulgated a move towards the 'total marketisation' of our lived experience (Harvey, 2005). In the UK, this process has overseen disinvestment in public services generally, and the very deliberate undermining of the embedded liberal social contract (Garett, 2019). This has included the selloff of nationalised industry, public utilities, transport and health and social welfare services (Jordan \& Drakeford, 2012). The constrained market of embedded liberalism was freed from barriers of regulation and unfettered access to both the public was handed over to private capital (Hill et al, 2019). The neoliberal strategy was operationalised through the defeat of organised labour; with the subsequent promotion of precarious low paid employment (Harvey, 2005). The hegemonic power of this economic period lies in its infiltration into the public imaginary, suggesting waste and inefficiency would be better managed by private interests, and securing support for the long held idea that what we once held in common, and collectively owned, was no longer in our public interest (Callaghan, 2000; Friedman, 2002).

Our discussion focuses on the shift in social welfare practices from the post-war social democratic period to the neoliberal period that currently dominates contemporary social work provision. The development of social work as a unique professional activity, 
reached its organisational zenith in the UK during the post-war period, peaking with the creation of social work departments and the role of generic social work in the late 1960s and early 1970s. (Hill et al, 2018; Payne, 2005). Social work formed part of an interconnected network of health, education, welfare and social services promoting a discourse in which the role of the state was to redistribute wealth and resources (Bamford, 2015; Frost \& Stein, 1989). The social, political and economic discourse viewed collectivisation of resources and the distribution of them as the best way to collectively manage poverty and inequality (Titmuss, 2019). This social state bound citizens together in a collective arrangement; the citizen was 'cared' for from 'cradle to grave'. The realities were not quite so clear cut. Overromanticizing the nature of this social contract, elides some of the power asymmetries involved, and the abuses of that power. Without dismissing the importance of this period in terms of the levels of care provided to its most needy citizens, it is equally important to reference Nancy Fraser's work on the triple movement (Fraser 2013). She critiques the 'Public Patriarchy' of welfarism and social protection, suggesting that the current crisis is a three-sided conflict among the forces of marketisation, social protection and emancipation. This position informs our work. In our critique of neoliberal marketisation we are not calling for a restoration of a social protection, which although affording relief from the disintegrative effects of marketization simultaneously entrenches domination. Rather we are examining the emergence of new practices, which have the potential to transform the service without a recourse to the politics of domination. 
The mantra 'business knows best' is central to the social experience of citizens in the UK. These processes have been underpinned by an official discourse, reframing the welfarist discourse as one focussed on a more punitive survivalist discourse (Wright \& Roberts, 2019). The neoliberal period has reduced bonds of kinship and community atomising the lived experience to one of isolated individualism (Beck et al, 2002). Attacks on the welfare state are accompanied by a discourse of rights allied to responsibilities, and this is where some of the greatest attacks on collective solutions to social problems have occurred. These changes were enacted through the widespread imposition of New Managerialism in the public sector, in particular social work and social service provision; which has seen a movement away from purely market based systems that were in place strictly for efficiency, to contractual mechanisms and performance measurement through audit and review (Rogowski, 2012).

With these critical theory positions, the paper has been derived from two ethnographic case studies, drawn from different social work organisations. The first is a statutory children's social work organisation (Agency A), and the second is a non-governmental organisation working with women engaged in street sex work (Agency B). Both organisations are institutionally diverse, with different legal functions, interventions and responsibilities. Using these organisations as case studies is important from a political, social and economic perspective. There is a theoretical position that NGOs offer a more social justice orientated and empowerment-based service and that local government social services are more focused on social order maintenance interventions (Hill et al, 2019). This is a false 
dichotomy, in the UK, social services have been reformed and outsourced on free market lines with much of the social welfare 'support' work outsourced to NGOs. Despite these significantly different institutional contexts, commissioning processes, and business practices of risk and care management; social work across public and private institutions remains grounded in the foundations of care, compassion, kindness and solidarity (Featherstone at al 2018; Ferguson et al, 2018).

\section{Methodology.}

In undertaking this qualitative research, both researchers were embedded within their respective organisations for twelve months undertaking ethnographic research. The researchers were independent and not employees of the organisations. The data collection methods used were participant observation and semi structured interviews; each researcher spending one day per week within their respective organisations. The participant observation process was an immersive experience allowing researchers to shadow social workers, attend team meetings, home visits and outreach support with their respective agencies. Observations permitted the researchers to observe the daily practices, administration, and response to crises. The process was captured using an ethnographic journal to collect surface level observational data (Gobo, 2008). These notes were developed into reflections forming part of the thematic analysis. Each researcher interviewed 10 social workers within their respective organisations. The semi-structured interviews took between 30 and 60 minutes depending on the participants availability. Data analysis was undertaken using an inductive six phase 
thematic analysis (Braun \& Clarke, 2006). We will explore three key themes that emerged from this process: social workers making time for service users, the importance of direct social support and the gendered nature of social work. These themes were then connected to larger macro, social, political and economic policy and critical theory, to contextualise the social work relationship in a wider global environment. The process of grounding macro theory in the everyday experience of practitioners is derived from the methodological position of Global Ethnography (GE), (Burawoy, 2000). GE helps the researcher to connect macro global forces, in this case neoliberalism, and explore it from the point of contact within micro community social work practice. This interconnection highlights the responses of social workers, noting the failure of contemporary neoliberal discourses to meet the needs of their clients, whilst continuing to provide interventions that while often hidden, provide a range of personal support and social care services to those in need.

\section{Resisting neoliberalism and new managerialism: 'Hands on' work and the art of}

\section{making time and 'seeing' service users.}

One of the themes emerging from observation within both Agencies A and B was the impact of New Managerialism on service provision. The discussion in this section highlights how macro theoretical concepts such a new managerialism shapes our everyday practice and can be grounded and explored within professional social work practice. In the public sector (and increasingly in NGOs) it involves the prioritisation of private (for-profit) sector values 
of efficiency and productivity in the regulation of public bodies, on the assumption that the former is superior to the latter (Harlow, 2003). Statutory social work in the UK has a professional culture focused on monitoring, surveillance, data recording and safeguarding (Hill \& Frost, 2018). As the socio-political context moved from collective redistribution of social and material resources, contemporary neoliberal social work became focused on rationing reduced resources and increasing technical specialisation within silos. Record keeping, monitoring and surveillance has always been a requirement of social work, but there has been a shift in the balance of workload since the late 1970s early 1980s from direct work to surveillance and recording (Bamford, 2015; Hill et al, 2019). The recording, monitoring and surveillance process in Agency A was directly observed as undermining and reducing the time that social workers had available to provide direct care and support to service users. Workers felt they were constantly juggling administrative demands and 'finding time'. This was in direct opposition to Agency B, where recording and monitoring was 'light touch' with a far greater emphasis placed on the importance of direct contact. Agency B is an NGO and could, for this reason, operate outside of the far narrower strictures of statutory bodies. As funding requirements dictate, more recently Agency B is engaged in far more multi-agency working, resulting in far greater levels of recording and monitoring than previously. Despite different organisational approaches social workers in both organisations placed great value on the direct work they undertook with service users, naming it the 'real work'. Everyone interviewed recognised the need for accurate records and sharing information as a professional requirement, and as a form of good practice. New Managerialism is now so 
integrated into professional practice, social workers in both organisations recognise the importance of sharing information and recording it to manage risk and safeguard individuals, families and communities. In this regard social workers are both subject to the power of new managerialism and as conduits for its reproduction; as monitoring, surveillance and safeguarding has become the new normal and a bastion of social work professionalism (Foucault, 1997)

Under the constraints of New Managerialism, the burden of administrative tasks for statutory social workers has not only grown, but the space to undertake tasks has been rationed and compartmentalised. Upon entering Agency A, watching the social workers practice in their office environment, my initial observation was that of a landing strip. The open plan office of Agency A with its tightly packed desks, left little room to manoeuvre. There was constant background hum from phone calls and informal discussions, the 'clickety-clack' of keyboards as social workers frantically typed reports to meet looming deadlines, all with pre-defined time scales required by the assessment process. The neoliberal office represents alleged efficiency and minimum cost through space maximisation; within Agency A efficiency was translated as a team of ten social workers supported by two administrators, working in confined conditions. Many of the social workers reported that they spent 'sixty to seventy percent' of their day undertaking administrative duties in the open plan office; not one of the social workers remarked on the conditions of the office; in the public sector, this confinement and rationalisation of space and resources has been normalised. 
This is in contrast to Agency B, which operates out of a small house. The interior of the house has been purposely designed as a dual space for workers and service users, although most of the space is given over to the service users and functions as a sanctuary offering safety and respite during the day. The office by necessity is located away from the service users and is a tiny box office, which suited previous ways of working, but given the increased demands for information sharing and meticulous record keeping in line with all multi-agency working, the office is now a very cramped space indeed. In keeping with the acceptance of facets of New Managerialism, social workers at Agency B, still define themselves much more in terms of their offer of direct support, and 'real work' but did not question the need for very detailed and meticulous note-keeping, report writing and information sharing. In fact, they used their status as an NGO to suggest that they kept more personal records along with personal artefacts (photographs of children, cards received from family members) from their clients, as a means of safekeeping. Their service users lead chaotic and transient lives', and so for the workers record keeping serves a different function. Nonetheless in my year of research at the Agency, I witnessed a much more demanding and rigorous procedure for the collecting and sharing of information.

Despite the length of time spent on recording and surveillance, all the social workers within Agency A reported that they wanted to spend 'more time' with the children, families and adults that they worked with. It is evident that the heart and soul of social work remains 
in the field, or as one statutory social worker remarked: "the hands-on work," another worker commented that the foundation of their practice is:

"Working with people, finding out more about them and understanding how their family dynamic works... when you see the progress with families, you get to the bottom of what the problems and difficulties are, you get that support in place. You help them understand that and overcome that, and then you can see the difference that it makes."

(Social Worker Agency A)

The staff at Agency B, all agreed that the most important part of their practice was

"The relational thing, the cuppa whilst catching up, asking small, seemingly insignificant questions, like how are you, and how's your day?"

(Social Worker Agency B)

The statutory social workers often felt that they had to make time, from other cases, often, their own personal time. In finding time for service users, social workers reported they frequently worked past their allotted office hours taking people to services or meeting the family on their own terms in the evening. This borrowing or making of time became acute when dealing with individuals in social crisis. The ability to shut down and compartmentalise is difficult in a direct social relationship with a family who are going without social and material resources. The constant need to make time and find space for people in need is an essential part of the social work relationship. The battle between administration, monitoring and time spent with service users leads into our next theme, the importance of direct care and social support. 


\section{The importance of direct care and social support}

In an environment where the technocratic practices of new managerialism have shaped social work practice, the discussion in this section highlights how macro theory such as new managerialism is grounded and explored from a critical micro perspective. Wherever a power relationship occurs resistance can be observed, however small, and our observations of micro practice, highlight resistance through the finding of extra time for direct care and support. In contemporary practice giving direct support and care and finding the time to do this has become a source of anxiety and distress particularly for social workers engaged in statutory practice (Featherstone et al, 2018). Social workers in Agency A routinely expressed the desire and the need to spend more time with service users. When asked what more time meant in an operational context, they articulated that it was the ability to 'give' more social support to people in a 'hands on' manner. Many of them reported that they were more akin to a 'signposting' service and repeatedly expressed a desire to get back to authentic 'direct work'. They felt aggrieved about handing over direct support to other agencies through referrals rather than dealing with the matter directly themselves. In their eyes the act of hands on direct work was something that should be hidden or removed from the visible process of statutory work, one worker apprehensive and unsure reported:

“But you can't do it... I think some workers do really get involved and go the extra mile. I suppose it's about who you are as an individual worker. The service can come across as so good or so poor depending on which worker you were allocated." (Social Worker, Agency A) 
This reveals a clear difference in culture and practice between the two Agencies. Staff at Agency B. were given time and valued this time to nurture and build strong relationships with their clients. It was clear that building a strong sense of a caring community lay at the heart of their practice and was fundamental to their work. It was summed up like this:

"It's really important for our women, to know that someone cares, that the person in front of them thinks they matter, that they are valued as human beings, and that their life has meaning, we can do this by sitting with them and listening to them" (Social Worker, Agency B)

Agency A had a structural culture of promoting relationship-based practice, and all the social workers identified relationship-based practice as the core of social work. However, the relationship was always framed within a safeguarding and statutory context placing limitations on how it is operationalized. This is in stark contrast to the methodology of Agency B where all workers were very hands on, administrative tasks are kept to a minimum and completed at the end of the day once the service users have left. As a result, there is a high level of practical support on offer to the women who access the project, helping to sort out problematic substance abuse, housing, medical issues or benefits. This very supportive approach results in a well-developed understanding of the complexities of the lives of the service users, and because of this, their provision goes beyond offering solely instrumental help and openly provides emotional support, friendship and community. The importance of building a trusting relationship with the service users was emphasised by the participants, and 
there was agreement that the basis of the relationship was 'knowing each and every one of the women', lots of time is spent just chatting, not auditing, or checking up, but having 'normal, everyday chats about life and love'. The social workers in Agency B refer to this as the 'humpty dumpty approach,' meaning that in their professional role it is more important to 'hold someone together' when they're down, rather than trying to fix them before they are in the right space. The idea of 'holding' is important to underscore the non-judgemental approach and demonstrates to the service users that there is no expectation on how and when a woman engages, that is up to her. The project promotes a person-centred approach underscoring the physical space as a recovery community, a place where the touchstones are support, solidarity and building community (Laredo \& Chiosso, 2018).

In Agency A the process of undertaking direct work was seen as an individual act of resistance to the bureaucratic professional process of social work; it was observed and described as the act 'of going the extra mile' and was often 'dependant' on which worker a service user received. There is no suggestion of a false dichotomy, of the good or bad practitioner; we are describing a process where statutory social work is shaped by a policy context that promotes surveillance, safeguarding and monitoring over direct care and social support. Receiving direct support and extra time for one to one work had become a discretionary activity in Agency A, given the demands of formal statutory safeguarding processes. Often the more experienced practitioners, those with 'time in service' made adaptations, offering extra time and support. The social workers in Agency A often reported having to buy essential items such as nappies and food for service users. In Agency A social 
workers reported that the current system of universal credit with its reduced social security was placing service users in social and material deprivation, resulting in, social injustice at a structural level. They argued that access to basic social material necessities is a fundamental human right and supported this process by direct care and social support, frequently bearing the cost themselves. The UK welfare system uses a model that places economic principles over social and material redistribution, it has been universally criticised by the United Nations for its unjust arrangements. In filling the social and material gaps of an unjust welfare system, social workers in Agency A reported that sometimes they were reimbursed by the agency for this, but often they were left 'out of pocket'. They reported making complex fictional narratives about sources of money, if it was not paid for by the agency, acutely aware that they did not want service users to know. Like a radical street level bureaucrat, they have adapted poor welfare policy and personalised it as an act of kindness, but this act represents something more, it becomes a process of solidarity where no person should be dehumanized and left without adequate social and material resources (Lipsky, 2010).

Agency B operates a low threshold approach, meaning it makes little or no demands on its service users, which is an important component of the support and care crucial to its core offer (Hill \& Laredo, 2019). Furthermore, in keeping with this approach the team have consciously eschewed a more traditional focus on targets and outcomes. This counterintuitive way of working means the social workers support their service users for as long they require. 
Like their counterparts in the statutory service, they work long hours to best support service users, but this work is acknowledged and recognized as being part and parcel of the radical community social work approach they have developed. One direct correlation in both agencies are the personalised responses to social crises. Personal responses to crises are of course simple acts of kindness, but in the current climate of managing caseloads efficiently, can be read as political acts of resistance, and the beginnings of a community social work approach based on solidarity. The personal becomes the political in a dominant social and economic narrative of individualisation. Examples of personal kindness as a form of solidarity is an important foundation from which individuals and practitioners develop a critique of the structural social, political, and economic narrative, and by extension the shaping of the services they are able to provide. Direct observations of poverty require immediate responses, and the ethical foundations of social work can be read as a complex mix of social justice, kindness, and solidarity. This ethical framework is shaped by the desire to help others. The concern for and assistance on offer, would suggest that despite the political economy of austerity and the technocratic imposition of New Managerialism and its shaping of contemporary practice, social workers themselves maintain a commitment to a set of deeply embedded principles of a rights based professional ethic (Ferguson \& Woodward, 2009; Hill et al, 2018). Budget constraints notwithstanding, the first response of social workers in both agencies is to' be with' families and individuals in need and position themselves alongside others to provide that direct support and care. Agency A support often includes providing a direct level of care; taking families to housing services, food banks, and 
other supportive agencies in the community to secure their necessary social and material resources to function within society; this direct support is not seen as a primary role of professional statutory social work, it is in addition to the safeguarding and monitoring they have to complete. For Agency B, direct care and support is a core requirement of practice and this approach was developed as a response to the multiple and complex needs of the women who access the service. The staff in Agency B understand both what motivates their service user group, and equally what deters them from accessing service provision. This knowledge is borne out of an approach that seeks to accompany the women who use the project, in their own words they 'journey with women', rather than determine and define solutions for them (Laredo, 2020). For both sets of social workers a key point of contact for practical activity was supporting others in dealing with the broader social welfare related issues. Often the referral to children's social work for safeguarding assessment was underpinned by an extended social crisis that was related to broader social welfare needs such as housing, health care and education. There was a broad recognition of the need to get the 'basics right'; housing, welfare income, school, and health services, before beginning to address some of the more complex aspects of cases. Again, this is where the work of the different agencies diverged, for the statutory social worker the process of accompanying a service user was positioned as an act of support, albeit often hidden. In this service there was a broader feeling that taking people to services was undermining the self-care skills of adults and somehow beneath professional social workers. In contrast this was core business for Agency B. 
When social workers in Agency A were questioned about why despite structural opposition, they maintained a commitment to accompanying their clients to other professional visits, their answers had a lot in common with the practices in Agency B. Social Workers in both agencies, despite their apparent external differences, maintained a broad commitment to social justice; prioritising the mental and physical well-being of their clients, providing material support, if deemed necessary. To deliver a socially just, rights-based practice, social workers must build direct and meaningful relationships through dialogue with the service users (Freire, 1970). As Bauman (2009) highlights the individualisation of complex social problems and the breakdown of social welfare is one of the greatest contemporary social injustices we face. This was important as social workers in Agency A reported that service users secured better outcomes with a social worker present and support was faster: in short, direct advocacy works. The process of direct advocacy was more than a simple act of doing for, it was an intimate moment, of going with someone, of recognising an adult, or family in need and agreeing to give some of your time to them. This act of kindness or solidarity is the foundation of social support and direct care. These are the moments when people forge relationships. Time spent with an individual or family at the health centre, hospital, school, housing department or welfare centre is experienced by the social worker as a good bonding session, and as offering silent support to the client. All too frequently, these visits highlighted the complexities, the intricacies, and the general miserable nature of broader social welfare services. Support offered by a professional to a client in this situation 
results in a unique bond of social support, where the social worker is now not an adversary to be feared but an advocate: it changes the nature of the relationship.

\section{Grounding neo Liberalism through the helping relationship: Exploring the gendered nature of social work practice.}

The final theme, is the gendered nature of social work, and the importance of a feminist social work practice As an approach, it emphasises gendered analyses and solutions, democratized structures and processes, diversity, and inclusivity, linking personal situations with political solutions, and transformation at all levels of intervention. Feminist practice is based on a multisystemic approach, complementing, and extending strength-based social work. Women social workers and women service users have common experiences of gender, oppression, and discrimination, and this can be a foundation for a transformatory feminist practice (Dominelli \& Campling, 2002). The vision of feminist social work lies in the desire to go beyond simply helping women, children, and families to do more than endure the hardships of crisis, seeking to create new visions for a better provision of welfare.

In both agencies the work is done primarily by women for women, men remain absent. The marginalisation of men is a structural issue that is compounded by a means tested and punitive social welfare system (Featherstone et al, 2007). When men were present the woman often took the lead in communicating with the social worker, with the man playing a muted secondary role. If present, it was clear from the conversations that the service users did 
not want them included for many reasons some personal, some safeguarding related, but, there was also a hidden economic motive for this as welfare and housing in the UK is premised on eligibility and determined by need and priority. The historical development of social work has always maintained gendered features in its operational context. As a form of care, it has been clearly situated in the domain of women's' work since its inception in the nineteenth century (Dominelli \& Mcleod, 1988). The family unit is one of the building blocks of capital, and the responsibility for the family has always been placed on women as unpaid carers and workers (Fraser, 2016).

The work in both agencies was very clearly one of women helping women through their crises. There is a synergy between the professional role of the social worker to produce self-caring and independent members of society, and role of parenting within the family (Weeks, 2009). In practice this is done through a process of engaging with others and their concerns, 'seeing them' understanding their lives, and their concerns. A feminist social work practice is clear about not holding women personally responsible for the socio-economic and political forces which cause the problems in the first place. Social workers in both agencies offered a clear understanding the gendered nature of structural inequalities their service users were facing. We observed them working in dynamic, creative, and supportive manner, using tools of empowerment as opposed to. Women have differentiated experiences of their oppression, and because of this intersectionality (Crenshaw, 2013) offers a framework that can be used to foster a more nuanced understanding of how interlocking oppressions manifest in everyday experiences for service users. In Agency A, women social workers from working 
class backgrounds disclosed that colleagues from different socioeconomic backgrounds had different expectations of service users. As working-class women and social workers, they would call on their female colleagues to adjust expectations in relation to direct contact with poverty, recognising that social work, in its managerial safeguarding role, was 'intrusive' and often 'unhelpful.' There was an implicit understanding that services users were 'making ends meet', but with little access to social and material resources, adhering instead to the age-old survival culture of working-class communities of 'getting by' and 'making ends meet' in difficult circumstances (McKenzie, 2015). In both agencies there was evidence of social workers desire to work with service users not just to get by but working with them in an informed and empowered manner to overcome the difficulties they and their families experienced.

\section{Conclusion}

To summarise our observations, highlight that the global forces of neo liberalism and the subsequent transformation of social services in the UK are located in every day micro practices. As an accompaniment to this, a narrative that 'this is just how things are', 'the way it is', and 'there is no alternative to the present system' has become pervasive. Our research has shown that actually there are challenges to this monolithic narrative. We observed a more nuanced practice, which we reframed as resistant to this ideology. Despite witnessing a service that has become fragmented, silo-based and reduced to an individualised model of 
risk management and behaviour modification, we found a practice concerned with the promotion of social justice, social solidarity and kindness. These points of resistance may be small, but they are the foundation from which the helping relationship is being reimagined, from one of control and social order to one, which promotes human rights and social justice. Valorising acts of personal acts of kindness and reframing them as public solidarity, introduces a public and political discussion, which underscores the current failures of the welfare system premised as it is on dependency. As Fraser (2013) argues, casting caring as a matter of public importance allows for a re-envisioning of social arrangements for everyone. As Fraser (2013) argues, casting caring as a matter of public importance allows for a reenvisioning of social arrangements for everyone. 


\section{Reference List.}

Ahmed, S. (2017) Living a Feminist Life. London, Duke University Press

Bailey, R and Brake, M (1975) Radical Social Work. London: Edward Arnold.

Bamford, T. (2015) A contemporary history of social work: learning from the past. Bristol: Policy Press.

Baum, N. (2016) 'The Unheard Gender: The Neglect of Men as Social Work Clients', British Journal of Social Work, 46(5), pp. 1463-1471.

Beck, U. and Beck-Gernsheim, E. (2002) Individualization: institutionalized individualism and its social and political consequences. London: SAGE.

Beckett, J. P. (2018) ‘The Changing Nature of Social Work', International Social Work, (Issue 6), p. 968.

Braun, V \& Clarke, V (2006) Using thematic analysis in psychology, Qualitative Research in Psychology, 3:2, 77-101.

Bauman, Z. (2009) The absence of society. In: Utting, D. (ed). Contemporary social evils. Bristol: policy Press - Joseph Rowntree Foundation.

Beck. U (1999) World Risk Society. London: Polity. 
Burawoy, M., Blum, J.A., George S., Gille, Z., Gowan, T., Haney, L., Klawiter, M., Lopez, S.H., Rian, S.O \& Thayer, M. (2000) Global Ethnography. Berkeley: University of California Press.

Callaghan, J. (2000) The retreat of social democracy. Manchester: Manchester U.P.

Crenshaw, K. (2103) Toward a Field of Intersectionality Studies: Theory, Applications, and Praxis Signs: Journal of Women in Culture and Society 38(4) p. 785

Dominelli, L. and McLeod, E. (1988) Feminist social work. Macmillan Education (Critical texts in social work and the welfare state). London: Macmillan Education.

Dominelli, L. and Campling, J. (2002) Feminist social work theory and practice. London: Palgrave

Featherstone, B., Rivett, M. and Scourfield, J. (2007) Working with men in health and social care. London: SAGE.

Featherstone, B; Gupta, A; Morris, K \& White, S (2018) Protecting Children A Social Model. Bristol: Policy Press.

Ferguson, I. and Woodward, R. (2009) Radical social work in practice: making a difference. Bristol: Policy. 
Ferguson, I: Ioakimidis, V. and Lavalette, M. (2018) Global social work in a political context: radical perspectives. Policy Press.

Fraser, N. and Nash, K. (2014) Transnationalizing the public sphere. [electronic resource]. Cambridge: Polity.

Fraser, N. (2013) The Fortunes of Feminism: From State-Managed Capitalism to Neoliberal Crisis London: Verso

Freire, P. (1970) Pedagogy of the Oppressed London: Penguin

Foucault, M. (1997) Discipline \& Punish, the Birth of the Prison. London: Penguin.

Foucault, M. \& Chomsky, N. (2011). The Chomsky - Foucault Debate. Human Nature:

Justice Vs Power. London: Souvenir press.

Garrett, P. M. (2019) 'What are we talking about when we talk about 'Neoliberalism”?', European journal of social work, (2), p. 188.

Gobo, G. (2008) Doing ethnography. London: SAGE.

Hanisch, C. (1969) The Personal is Political in Notes From the Second Year of Women's Liberation accessed http://library.duke.edu/rubenstein/research/citations-and-permissions accessed 07/05/20 
Harris, J (2008) 'State Social Work: Constructing the Present from Moments in the Past', The British Journal of Social Work, 38(4), p. 662.

Harvey, D. (2005) A Brief History of Neo Liberalism. Oxford: Oxford University Press.

Harlow, E (2003) New managerialism, social service departments and social work practice today, Practice, 15:2, 29-44.

Harvey, D. (2005) A Brief History of Neo Liberalism. Oxford: Oxford University Press.

Hill, D; Mercer D; Agu, L (2018) Exploring and Locating Social Work: A Foundation for Practice. Basingstoke- England: Macmillan International - Red Globe Press.

Hill D; Penson B; Charura D (2015) Working with Dual Diagnosis A Psychosocial Perspective. Basingstoke- England: Palgrave Macmillan.

Hill D; \& Frost N (2018) Social work in England: regulation, competition, and change. In: Hill DJ; Frost N TRABAJO SOCIAL EN EL SIGLO XXI: Desafíos para la formación académica y profesional. Social Work in the XXI st century: Challenges to educational and professional training. Dykinson: Madrid.

Hill, D; \& Laredo, E (2019), First and last and always: Streetwork as a methodology for radical community social work practice. Critical and Radical Social Work. 7:1, 25-41. 
International Federation of Social Workers (2012) [Internet] Global Standards. Available from <https://www.ifsw.org/global-standards/> [Last Accessed October 14, 2019]

Jordan, B. \& Drakeford, M. (2012) Social Work and Social Policy Under Austerity. Basingstoke: Palgrave Macmillan.

Laredo EA; Chiosso RM (2018), The tensions and potential limitations of working with vulnerable groups; women sex workers in Holbeck, Leeds. Radical Community Work Journal, vol. 3 (1).

Laredo, E.A (2019), The Joanna Project: a faith-based project supporting street sex workers in Leeds. Radical Community Work Journal, vol. 3 (2).

Laredo, E.A. (2020) Love Actually: Reflections on the Importance of a Love Ethic in Practice Radical Community Work Journal vol.4 (4).

Jensen, T\& Tyler, I. (2015) Benefits broods: the cultural and political crafting of anti-welfare common sense Critical Social Policy 4 (35)

Lipsky, M. (2010) Street level Bureaucracy: Dilemmas of the individual in public Services. New York: Russel Sage Foundation.

McKenzie, L. (2015) Getting by: Estates, class and culture in austerity Britain. Bristol: Policy Press. 
Payne, M. (2005) The origins of social work: continuity and change. Basingstoke- England: Palgrave Macmillan.

Polanyi, K (2001) The Great Transformation. Boston: Beacon Press.

Rogowski, S. (2012) 'Social Work with Children and Families: Challenges and Possibilities in the Neo-Liberal World', British Journal of Social Work, 42(5), pp. 921-940.

Thompson, L; Rickett, B \& Day, K (2018) Feminist Relational Discourse Analysis: putting the personal in the political in feminist research, Qualitative Research in Psychology, 15:1, 93-115, DOI: 10.1080/14780887.2017.1393586

Titmuss, R.M. (2019) Essays on the Welfare State. Bristol: Policy Press.

Weeks, K. (2011) The Problem with Work. London: Duke University Press.

White, V. (2006) The state of feminist social work. London: Routledge.

Wright, S. and Patrick, R. (2019) 'Welfare Conditionality in Lived Experience: Aggregating Qualitative Longitudinal Research', Social Policy \& Society, 18(4), p. 597. 
